\title{
Allergy to laboratory animals in children of parents occupationally exposed to mice, rats and hamsters
}

\author{
A. Krakowiak, B. Szulc, P. Górski
}

\begin{abstract}
Allergy to laboratory animals in children of parents occupationally exposed to mice, rats and hamsters. A. Krakowiak, B. Szulc, P. Górski. (C)ERS Journals Ltd 1999.

ABSTRACT: Sensitization to laboratory animals (LA) has a high prevalence among laboratory workers. It is unknown whether transportation of $\mathbf{L A}$ allergens can be a risk factor for sensitization of subjects outside the laboratory environment. The aim of the study was to investigate the prevalence of sensitization to LA among children whose parents were and were not occupationally exposed to LA.

The first group consisted of 50 children (age 12.3 $\pm 4.3 \mathrm{yrs}$ ) whose parents were occupationally exposed to mice, rats and hamsters. The second group consisted of 40 children (age (mean \pm SD) $10.8 \pm 3.0$ yrs) whose parents were not occupationally exposed to LA. Children having LA at home were eliminated from the study. All children responded to a questionnaire, underwent spirometry and were also tested with skin prick tests with the use of common allergens and prick tests with hair extracts from mouse, hamster and rat. Total immunoglobulin (Ig)E levels and the presence of specific IgE against LA were also estimated.

Children of parents occupationally exposed to LA presented significantly more positive skin prick tests against allergens from the hair of laboratory animals compared to children of nonexposed parents. Five children from the first group were also found to have specific IgE against LA, with three of these five children complaining of rhinitis and cough while visiting their parents' workplace.

It is concluded that the observed increased sensitization to laboratory animals among children of occupationally exposed parents could be the result of poor hygienic conditions at their parents' workplace. Hence, parents' job seems to be an additional risk factor of sensitization and should be taken into consideration when recording an allergic history.

Eur Respir J 1999; 14: 352-356.
\end{abstract}

Several epidemiological studies in recent years indicate that the prevalence of allergic diseases is on the increase. For example, asthma is currently the most common of all chronic diseases of childhood. Factors that appear to place a child at risk of allergy include heredity, the presence of atopy, exposure to allergens, viral infections and air pollutants [1]. Based on this knowledge, when recording the history of the young patient, their exposure to allergens and the presence of allergic diseases in his parents is questioned. So far, when diagnosing allergic children, their parents' job and occupational exposure to allergens is not taken into account.

This study asked whether children of parents occupationally exposed to laboratory animals are at a higher risk for the development of allergy, and hence, should parental occupation be considered when diagnosing allergy in children. Firstly, the prevalence of sensitization to laboratory animals among children of parents occupationally exposed to laboratory animals was investigated in order to show that parents' job might be an additional risk factor for the development of allergic disease. The children of occupationally exposed parents were then compared with children whose parents were not occupationally exposed to laboratory animals. In this part of the study, their changes in lung function, allergic symptoms and atopic status were compared.
Dept of Occupational Diseases Nofer Institute of Occupational Medicine Lódz, Poland.

Correspondence: P. Górski

Nofer Institute of Occupational Medicine Dept of Occupational Diseases

8 Teresy St P.O. Box 199

90-950 Lódz, Poland

Fax: 426314764

\section{Keywords: Allergy}

children

laboratory animals

parents' job

Received: May 151998

Accepted after revision March 31999

This work was supported as part of the Strategic programme of Polish Government - Strategy for Poland 2000.

\section{Subjects}

There were two groups of children participating in the study. The first group consisted of 50 children (age (mean \pm SD) $12.3 \pm 4.3$ yrs) of parents who were occupationally exposed to laboratory animals, such as mice, rats and hamsters for at least $1 \mathrm{yr}$ (the longest period of parental exposure to LA was $35 \mathrm{yrs}$ ). The second randomized group consisted of 40 children (age $10.8 \pm 3.0$ yrs) of parents without occupational exposure to laboratory animals. Children having laboratory animals at home were eliminated from the study.

\section{Questionnaire}

Individual characteristics were determined from a questionnaire and upon physical examination. Questions of interest for this study were family history of atopy or allergic diseases, past history of respiratory disease, allergic symptoms specific for bronchial asthma, the presence of laboratory animals at parents' work, the presence of animals at home (e.g. cat, dog) and the smoking habits of parents. 


\section{Physical examination and lung function testing}

In addition to the physical examination, resting spirometry with the estimation of forced vital capacity (FVC) and forced expiratory volume in one second (FEV1) by a spirometer (Vicatest 2A; Vicatest, Mijnhardt, Holland) were determined.

\section{Skin prick testing}

In all children, standard skin prick tests with the use of common allergens and prick test with hair extracts from the mouse, rat, hamster, cat and dog (house dust mite, Dermatophagoides pteronyssinus, feathers, moulds, grass and tree pollens; Allergopharma, Reinbek, Germany) were performed. A negative control was made with the allergen diluent and a positive control with histamine solution. All the tests were examined after 20 min grading of the weal ( $\geq 4 \mathrm{~mm}$ larger than the control was considered positive) and flare ( $\geq 5 \mathrm{~mm}$ larger than the control was considered positive) reaction was conducted following standard methods. Additionally, serum levels of total immunoglobulin (Ig)E (Pharmacia, Uppsala, Sweden) and specific IgE antibodies for laboratory animal allergens by radioallergosorbent test (RAST; Pharmacia) were evaluated.

All children and their parents were informed about the experiment and the tests were performed after obtaining their consent to participate in the study. The study was approved by the local medical ethical committee.

\section{Definitions}

In the analysis of the data, the following definitions of sensitized and allergic subjects were used. An individual was considered sensitized to laboratory animals if they had a positive skin prick test or specific serum $\operatorname{IgE}$ to the allergen. Subjects were considered allergic to laboratory animals if they were sensitized and showed evidence of respiratory symptoms, such as rhinitis, wheezing, tightness of the chest or coughing that were clearly related to laboratory animals.

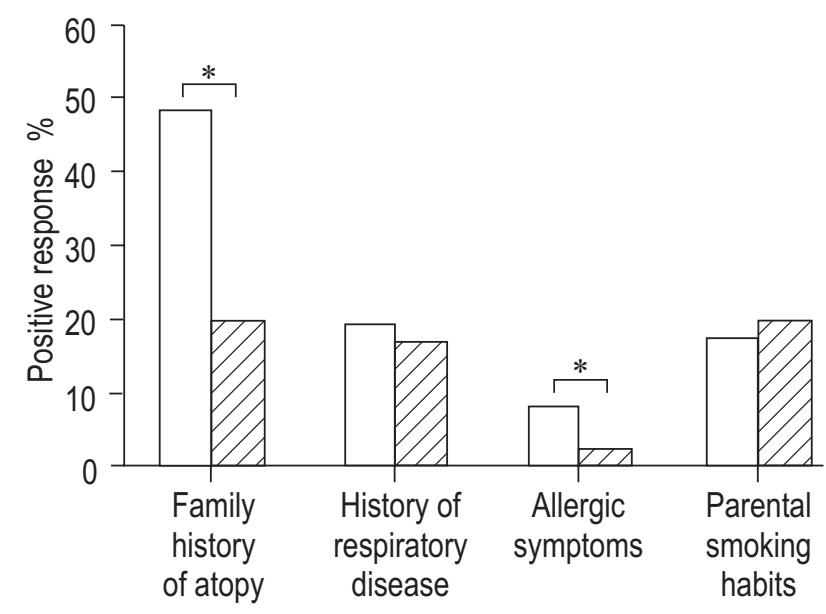

Fig. 1. - Frequency of positive responses to selected questionnaire items in children of parents with $(\square)$ and children of parents without $(\mathbb{Z})$ occupational exposure to laboratory animals. *: $\mathrm{p}<0.05$, Fisher's exact test.
Table 1. - Lung function, total immunoglobulin (Ig)E and specific IgE to laboratory animal allergens

\begin{tabular}{lcc}
\hline & $\begin{array}{c}\text { Children of parents } \\
\text { with occupational } \\
\text { exposure }\end{array}$ & $\begin{array}{c}\text { Children of parents } \\
\text { without occupational } \\
\text { exposure }\end{array}$ \\
\hline FVC L & $2.42 \pm 0.35$ & $2.39 \pm 0.32$ \\
FEV 1 L $\cdot \mathrm{s}^{-1}$ & $1.76 \pm 0.23$ & $1.65 \pm 0.55$ \\
IgE IU.L & $45 \pm 15$ & $41 \pm 14$ \\
RAST & 5 & 0 \\
\hline
\end{tabular}

Data are mean \pm SD. *: Number of children with a positive test. FVC: forced vital capacity; FEV1: forced expiratory volume in one second; RAST: radioallergosorbent test.

\section{Statistical analysis}

Statistical analyses were performed using Student's, Chi-squared or Fisher's exact test. To evaluate which variables were related to respiratory symptoms, lung function and sensitization, an analysis of logistic regression was used.

\section{Results}

A positive family history of atopy or asthma was reported more frequently by children of parents with occupational exposure than by children of parents not occupationally exposed to laboratory animals (48.6 versus $20.4 \%, \mathrm{p}<$ 0.001 , Fisher's exact test, fig. 1). Ten children from occupationally exposed parents $(20 \%)$ and seven from the nonexposed parents $(17.5 \%)$ reported previous recurrent bronchitis, chronic sputum production or pneumonia $(\mathrm{p}>$ 0.1 ), but there was no significant difference between these groups. There was a significant difference in the frequency of symptoms suggestive of airways allergic disease, such as asthma and rhinitis between the children of occupationally exposed and nonexposed parents (8 versus $2 \% \mathrm{p}<0.05$, Fisher's exact test, fig. 1).

There was no significant difference in the frequency of parental smoking habit between the two groups (17 versus $20 \%$ p $>0.05$, Fisher's exact test, fig. 1).

There was no difference in FVC and FEV1 between the two groups of children (Student's test, $\mathrm{p}>0.05$, table 1). Similarly, serum levels of total $\mathrm{IgE}$ were not different in children from both groups (Student's test, $\mathrm{p}>0.05$, table $1)$.

However, five children of occupationally exposed parents showed specific IgE antibodies to those allergens, although there were no such animals in their home environment (table 1). Three of these 5 children complained of rhinitis and cough while visiting their parents' workplace.

The absolute numbers and percentage counts of positive skin prick test against the common allergens are summarized in figure 2. Overall, there was no significant difference in the frequency of positive tests to common allergens between two groups ( $p>0.05$, Fisher's exact test). However, a difference in the absolute numbers and percentage counts of positive skin prick tests against allergens of mouse, rat and hamster hair extracts was observed. Children of occupationally exposed parents presented significantly more positive skin prick tests against allergens from the hair of laboratory animals $(\mathrm{p}<0.05$, Fisher's exact test, fig. 3). Furthermore, the 


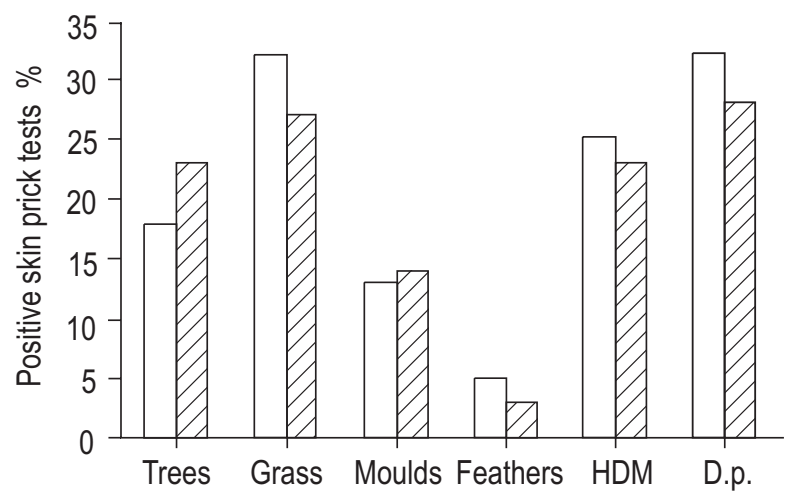

Fig. 2. - Frequency of positive skin prick tests against common allergens in children of parents with $(\square)$ and children of parents without $(\mathbb{Z})$ occupational exposure to laboratory animals. HDM: house dust mite; D.p.: Dermatophagoides pteronyssinus.

percentage counts of positive skin tests against hair allergens of cat and dog were significantly higher in the group of children from parents exposed to laboratory animals $(\mathrm{p}<0.05$, Fisher's exact test, fig. 4).

\section{Risk factors}

Stepwise logistic regression was used to determine factors that may influence the development of respiratory symptoms, lung function and sensitization. The items in the questionnaire were used as covariables. It was found that symptoms suggestive of airway disease in children were associated with the presence of pets in homes and with their parents occupational exposure to laboratory animals $\left(\mathrm{p}<0.05\right.$, Pearson's $\chi^{2}$ test $)$.

There was a significant association $(\mathrm{p}<0.05$, Pearson's $\chi^{2}$ test) between positive skin prick tests to laboratory animals in children and the occupational exposure of their parents.

Furthermore, there was a significant association ( $\mathrm{p}<$ 0.05 , Pearson's $\chi^{2}$ test) between a positive RAST to hair allergens of laboratory animals and the occupational exposure.

No association between a positive RAST to hair allergens of laboratory animals and smoking status of parents in both groups ( $\mathrm{p}>0.05$, Pearson's $\chi^{2}$ test) was observed (table 2).

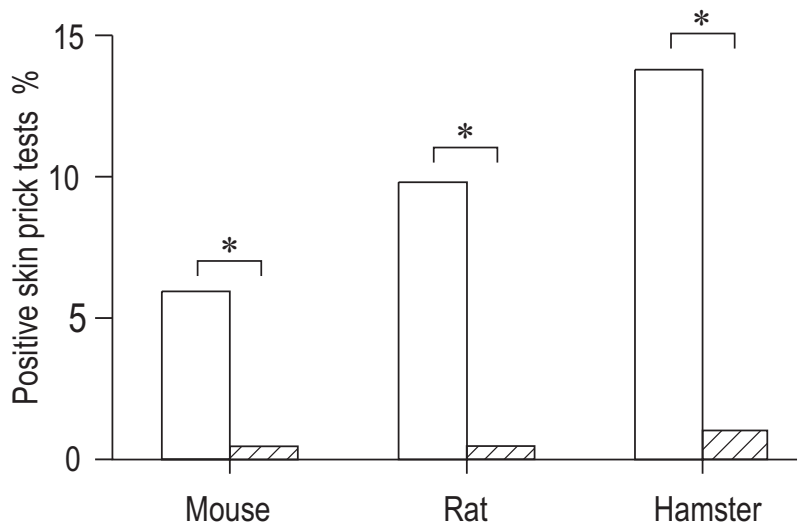

Fig. 3. - Frequency of positive skin prick tests to laboratory animal allergens in children of parents with $(\square)$ and without $(\mathbb{Z})$ occupational exposure to laboratory animals. ${ }^{*}: \mathrm{p}<0.05$, Fisher's exact test.

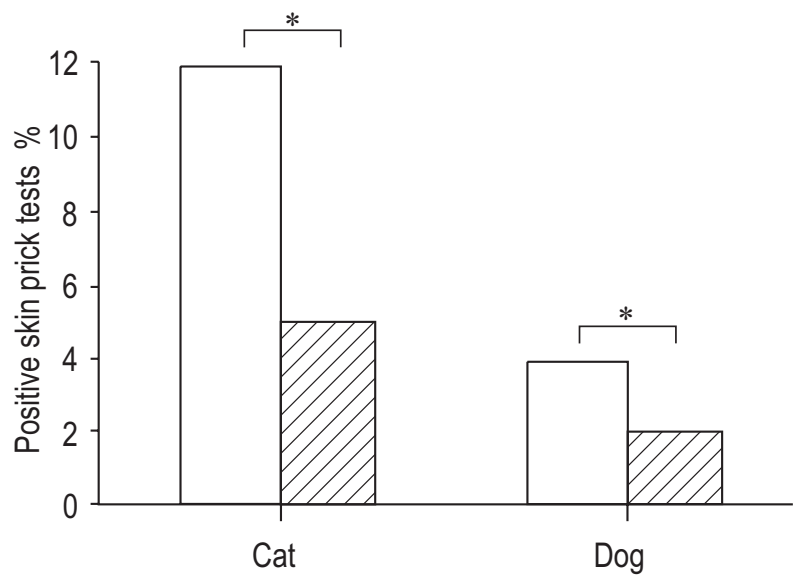

Fig. 4. - Frequency of positive skin prick tests to hair allergens of cat and dog in children of parents with $(\square)$ and children of parents without $(\mathbb{Z})$ occupational exposure to laboratory animals. *: $\mathrm{p}<0.05$, Fisher's exact test.

\section{Discussion}

The relative risk of, and the tendency to develop allergic disease early in life are both strongly influenced by genetic factors and a family history of allergic disease $[2,3]$. In the authors opinion, parental occupation appears to be an important risk factor for the development of allergic disease.

This study of children whose parents had been exposed to laboratory animals at work showed that the incidences of positive skin prick tests to animal allergens and positive RASTs had been higher than children of parents not occupationally exposed to laboratory animals.

The diagnosis of sensitization was based both on skin prick tests against hair allergens from the commonly used laboratory animals, and supplemented by measuring specific IgE in serum. Only five children from the occupationally exposed group had both positive skin prick tests and positive RASTs against hair allergens. Several studies show, however, that specific IgE cannot be demonstrated with the methods available in many subjects who experience symptoms. These five children visiting their parents' work at least three times per year (range 2-6 visits) had been in contact with laboratory animals for at least 5 min (range 5-15 min). The other five children, that had only positive skin prick tests to laboratory animals had never seen their parents' workplace. All children from the occupationally exposed group had been in contact with their parents' clothes, which had been brought home from the workplace many times per year (range 4-10 times). Three children with positive skin prick tests to laboratory animals and with specific IgE, and the three that had only positive skin prick tests to laboratory animals without a positive RAST possessed a cat at home. Two children with only positive skin prick tests to laboratory animals possessed a dog at home. Recently, some authors have noticed that allergy to cats or dogs seemed to be an important risk factor for laboratory animal allergy from the result of adverse reactions between these allergens [4]. Albumins occur at high concentrations in animal hair/dander extracts and represent important cross-reactive allergens for $\sim 30 \%$ of patients with animal allergy $[5,6]$. Patients allergic to animals frequently display IgE reactivity to 
Table 2. - Factors that may influence the development of respiratory symptoms and sensitization in children

\begin{tabular}{lccc}
\hline & $\begin{array}{c}\text { Presence of } \\
\text { pets in } \\
\text { homes }\end{array}$ & $\begin{array}{c}\text { Occupational } \\
\text { exposure to } \\
\text { laboratory } \\
\text { animals }\end{array}$ & $\begin{array}{c}\text { Parental } \\
\text { smoking } \\
\text { habit }\end{array}$ \\
\hline $\begin{array}{l}\text { Allergic symptoms } \\
\text { Positive skin prick } \\
\text { tests to laboratory } \\
\text { animals }\end{array}$ & $\begin{array}{c}\mathrm{p}<0.05 \\
\mathrm{p}<0.05\end{array}$ & $\begin{array}{c}\mathrm{p}<0.05 \\
\mathrm{p}<0.05\end{array}$ & $\begin{array}{c}\mathrm{p}>0.05 \\
\mathrm{p}>0.05\end{array}$ \\
$\begin{array}{l}\text { Presence of spe- } \\
\text { cific IgE to labo- }\end{array}$ & $\mathrm{p}<0.05$ & $\mathrm{p}<0.05$ & $\mathrm{p}>0.05$ \\
ratory animal & & & \\
allergens & & & \\
\hline
\end{tabular}

IgE: immunoglobulin E.

hair/dander proteins from different animals. The presence of albumin in different animal hair/dander extracts can explain the occurrence of allergic symptoms in patients on contact with various animals.

The present study assumed that laboratory animal allergens had been present at home because of passive transport by parents who had been in contact with the allergens. D' АмАто et al. [7] found that the clothing was the source of cat allergens. The presence of an animal allergen in the home of a neonate, particularly if there is a family history of allergy, may thus increase the prevalence of allergy to that allergen several years later.

Two children from the nonexposed group had positive skin prick tests to hair extracts from laboratory animals, despite their parents not being occupationally exposed to mice, rats and hamsters. This may be the result of an increasing concentration of airborne animal allergens in Polish buildings. The majority of Polish families have at least one cat or dog, and some of them also have animals such as mice, rats or hamsters.

Over half of all homes in the United States contain at least one cat or dog, and cats are now slightly more common than dogs [8]. GoRDON [9] suggest that as cat and dog allergens can be detected in public places and homes without current pet occupation, the majority of the population may be at risk of sensitization to domestic animals. Thus, it is clear that the assessment of laboratory animal exposure, with regard to both sensitization and disease, should not be based solely on the presence or absence of laboratory animals in the home.

For example, cat allergens have been found in settled dust samples from homes without cats, as well as in every other building where they have been sought, including newly built homes and shopping malls $[10,11]$. It has been shown that even people who have never lived around cats become sensitized, implying that low-level exposure may at least be capable of inducing sensitization [12]. Perhaps in highly sensitive individuals, even very low airborne animal antigen concentrations might induce respiratory symptoms. For example, Bollinger et al. [13] noticed that the low level cat exposure that occurred in many homes without cats was capable of inducing symptoms in some patients who were sensitive to cats.

There was no difference in the total IgE level between the two groups of children. Unlike RENSTROM et al. [14], this study did not find that the best predictor for symptoms and sensitization was total IgE levels. Similarly,
Hollander et al. [4] described total $\mathrm{IgE}$ as a risk factor of laboratory animal allergy.

The present study found that both upper and lower respiratory diseases were more likely to occur in the group of children whose parents had been occupationally exposed to laboratory animals. It was also assumed that these children were more frequently exposed to higher animal allergen levels through their parents' occupation, although the airborne animal concentrations both at work and in their homes were not determined. EGGLESTON et al. [15] noticed that both nasal and bronchial symptoms were significantly dependent on the concentration of airborn rat allergens. Nasal symptoms were significantly increased at a rat allergen concentration of $166 \pm 28 \mathrm{ng} \cdot \mathrm{m}^{-3} \mathrm{com}-$ pared with $9.6 \pm 3 \mathrm{ng} \cdot \mathrm{m}^{-3}$, but the pulmonary response was similar in terms of symptoms, cough or FEV1. Three children from the first group with a positive skin prick test and RAST confirmed that nasal symptoms such as sneezing, itching and rhinorrhea had appeared before the development of chest symptoms (asthma) [14]. Some studies found that asthma without rhinitis was rare among subjects occupationally exposed to laboratory animals, and that most often it was associated with nasal symptoms [16].

As no significant difference was observed in the frequency of positive skin prick tests response to common allergens between the two groups of children, it could be supposed that allergy to common allergens does not appear to be an important risk factor for sensitization to laboratory animals. HoLLANDER et al. [17] noticed that allergy to cats or dogs seemed to be an important risk factor for laboratory animal allergy, whereas allergy to pollen or house dust mite, in the absence of cat and dog allergy, appeared to be insignificant.

Smoking is by far the most documented risk factor for the development of allergic diseases. Numerous epidemiological studies have found an association between exposure to tobacco smoke and recurrent wheezing, bronchial hyperreactivity and the diagnosis of asthma [18, 19]. An association between passive smoking and an increased risk of sensitization to environmental allergens has also been shown, in both clinical studies and animal experiments. Tobacco smoke has a direct irritant effect on the mucous membrane and thereby damages its surface, allowing penetration of allergens. Furthermore, tobacco smoke may have a direct immunomodulating effect [20]. However, several studies have reported the opposite results $[21,22]$.

Since no association was found between positive RAST to hair allergens of laboratory animals and smoking status of parents, and between smoking and positive skin prick tests to laboratory animal allergens and allergic symptoms in both groups, it is concluded that there is not sufficient evidence that smoking is a risk factor for laboratory animal allergy.

In summary, it can be concluded that parental occupation seems to be an additional risk factor for sensitization and should be taken into consideration in allergic history. It seems that atopy as shown by positive skin tests to cats and dogs seems to be an important risk factor for sensitization to laboratory animals. The study results showed that total the IgE level, especially a low level, is not the best predictor for symptoms and sensitization to hair allergens of mice, rats and hamsters. 
Future studies of larger groups of children, whose parents are occupationally exposed to laboratory animals and where the airborne concentrations of laboratory animal allergens both at work and in their homes have been determined, would be of interest to whether there is a correlation between the duration of parental exposure and the prevalence of children's sensitization to laboratory animal allergens.

\section{References}

1. Bjorksten B. Risk factors in early childhood for the development of atopic diseases. Allergy 1994; 49: 400-407.

2. Warner JA, Little SA, Pollock I, Longbottom JL, Warner JO. The influence of exposure to house dust mite, cat, pollen and fungal allergens in the home on primary sensitization in asthma. Pediatr Allergy Immunol 1990; 1: 79-86.

3. Lympany P, Welsh K, Cochrane G, Kemeny DM, Lee TH. Genetics analysis of the linkage between chromosome 11q and atopy. Clin Exp Allergy 1992; 22: 1085-1092.

4. Hollander A, Doekes G, Heederik D. Cat and dog allergy and total $\operatorname{IgE}$ as risk factors of laboratory animal allergy. $J$ Allergy Clin Immunol 1996; 98: 545-554.

5. Spitzauer S, Pandjaitan B, Muhl S, et al. Major cat and dog allergens share IgE epitopes. J Allergy Clin Immunol 1997; 99: 100-106.

6. Spitzaur S, Schweiger C, Sperr WR, et al. Molecular characterization of dog albumin as a cross-rective allergen. J Allergy Clin Immunol 1994; 93: 614-627.

7. D'Amato G, Liccardi G, Russo M, Barber D, D'Amato M, Carreira J. Clothing is a carrier of cat allergens. J Allergy Clin Immunol 1997; 99: 577-578.

8. United States Bureau of the Census. 1994 Statistical Abstract of the US. 14th Edn. Lanham, Maryland, Bernan Press, 1994; p. 254.

9. Gordon S. Allergy to furred animals. Clin Exp Allergy 1997; 27: 479-481.

10. Enberg RN, Shame SM, McCullough J, Ownby DR. Ubiquitous presence of cat allergen in cat-free buildings: a probable dispersal from human clothing. Ann Allergy 1993; 70: 471-474.
11. Luczynska CM, Yin L, Chapman MD, Platss-Mills TAE. Airborn concentrations and particle size distributaion of allergen derived from domestic cats (Felis domesticus). Am Rev Respir Dis 1990; 141: 361-367.

12. Munir AKM, Einarsson R, Kjellman N-IM, Bjorksten B. Mite (Der p I, Der f I) and cat (Fel d I) allergens in the homes of babies with a family history of allergy. Allergy 1993; 48: 158-163.

13. Bollinger ME, Eggleston PA, Flanagan E, Wood RA. Cat antigen in homes with and without cats may induce allergic symptoms. J Allergy Clin Immunol 1996; 97: 907914.

14. Renstrom A, Malmberg P, Larsson K, Sundblad BM, Larsson PH. Prospective study of laboratory animal allergy: factors predisposing to sensitization and development of allergic symptoms. Allergy 1994; 49: 548-552.

15. Eggleston PA, Ansari AA, Adkinson NF, Wood RA. Environmental challenge studies in laboratory animal allergy. Effect of different airborn allergen concentrations. Am J Respir Crit Care Med 1995; 151: 640-646.

16. Krakowiak A, Szulc B, Gorski P. Occupational respiratory diseases in laboratory animal workers: initial results. Inter J Occup Med and Environ Health 1997; 10: 31-36.

17. Hollander A, Doekes G, Heederik D. Cat and dog allergy and total $\mathrm{IgE}$ as risk factors of laboratory animal allergy. $J$ Allergy Clin Immunol 1996; 98: 545-554.

18. Kjellman NIM. Effect of parental smoking on IgE levels in children. Lancet 1981; 1: 993-994.

19. Murray A, Morrison B. The effect of cigarette smoke from the mother on bronchial responsiveness and severity of symptoms in children with asthma. J Allergy Clin Immunol 1986; 77: 575-581.

20. Schmitt M, Gruters A, Beck H, et al. Does passive smoke lead to decrease of CD4+ lympocytes in infants. Allergy 1992; 47 (Suppl. 12): 17.

21. Agrup G, Belin L, Sjostedt L, Skerfving S. Allergy to laboratory animals in laboratory technicians and animal keepers. Br J Ind Med 1986; 43: 192-198.

22. Slovak AJM, Hill RN. Laboratory animal allergy: a clinical survey of an exposed population. $\mathrm{Br} J$ Ind Med 1981; 38: 38-41. 